\title{
Correction of a Popular Error in the Optimization Design of Helical Springs
}

\author{
Yongxian Li, Mibao Wang, and Ru Liu
}

\begin{abstract}
In the optimized design of helical springs, wire diameter $d$, mean coil diameter $D$ and number of active coils $n$ as design variables are a prevalent mistake. This paper analyzes and demonstrates this error. When loads $F_{1}, F_{2}$ and deflections $\lambda_{1}, \lambda_{2}$ are known, the number of active coils $n$ is the dependent variable of wire diameter $d$ and mean coil diameter $D$ in the formula of $n$. It is known that if some design variables are dependent variables, there must be some equality constraints between them. Almost none of monographs has constrained the number of active coils $\boldsymbol{n}$ by equality constraint as yet. Therefore, in most optimization results of helical springs the number of active coils $n$ is wrong, where value of $n$ is not calculated by the formula of $n$. The formula of shear stress in spring shows that the wire diameter $d$ and the mean diameter $D$ are independent variables. The wire diameter $d$ and the mean diameter $D$ as design variables are more reasonable in the actual optimization process of helical springs design. Reducing the three design variables to two design variables not only can meet the requirements of the design objective of helical springs but also can significantly improve the efficiency of the helical springs optimization.
\end{abstract}

Index Terms-Helical springs, optimization design, number of active coils $n$, design variable, dependent variable.

\section{INTRODUCTION}

Helical springs are common and important elements in mechanical design. Helical spring design is dependent on numerous variables, and it is difficult by trial-and-error methods to find the most efficient design [1]. Althrough detailed methods for analyzing and designing such mechanical components have been developed over the years (e.g., Spotts, 1953; Wahl, 1963; Shigley, Mischke, and Budynas, 2004; Haug and Arora, 1979) [2], it is hard to design satisfactory results by using these methods. Optimization design is an important means to ensure the spring performance, so that the optimum design of spring has generated widespread interest and utilize among engineers and researchers.

Singh and Kulkarni [3] gave a graphical method for optimal design of a general purpose helical spring for minimum weight. The method is based upon a direct method

Manuscript received November 10, 2016; revised March 1, 2017.

Yongxian $\mathrm{Li}$ is with the Department of Automotive Engineering, Weifang Business Vocational College, Weifang, CO 262234 China and with the College of Engineering, Zhejiang Normal University, Jinhua, CO 321004 China. He was with the Tan Kan Ken College, Xiamen University, Xiamen, CO 363105 China and with the School of Automotion and Transportation, Tianjin University of Technology and Education, Tianjin, CO 300222 China (e-mail: lyx3210@ 126.com).

Mibao Wang and Ru Liu are with the Department of Automotive Engineering, Weifang Business Vocational College, Weifang, CO 262234 China (e-mail: wmbxm@163.com,1014998122@qq.com). of constrained optimization. A numerical example is solved and the spring parameters are determined for minimum weight of the spring. A brief discussion of the paper is appended.

Azzam [4] performed an optimization study on helical compression springs. Two objectives are considered: the first objective is to minimize the spring weight, and the second is to maximize the spring stiffness. These two objectives are affected by many engineering design parameters, which can be categorized in three main groups: functional, composite material, and geometrical groups. The objective functions and constraints are mathematically formulated and written in a multi-criteria optimization problem with a non-linear non-equality constraints form. Optimum design parameters, minimum spring weight, and maximum stiffness pertinent to each type of composite material under investigation can then be selected from the results obtained.

Pöllänen and Martikka [5] obtained optimum design of the spring. Goals are minimisation of wire volume, space restriction, desired spring rate, avoidance of surging frequency and achieving reliably long fatigue life.

Fan, Wu, Luan and Wang [6] established a multi-objective optimization model of automobile suspension helical spring which is based on the Matlab optimization design platform by taking the automobile suspension helical spring as the research object and using Pareto optimization theory and particle swarm optimization algorithm. The purpose is to seek for the optimal structure design proposal which is under the objective of maximum natural frequency and minimum quality of spring. The Pareto optimal solution set is obtained.

Mohamed, Khalifa, Abdessattar, Fakhreddine and Mohamed [7] proposed a numerical method to model the dynamic behavior of an isotropic helical spring. In the proposed dynamic optimization problem, four geometric parameters are chosen as design variables (wire diameter, middle helix diameter, active coils numbers and spring pitch). In addition of mechanical and geometrical constraints, dynamic ones related to natural frequencies of the helical spring are added. Two objective functions are chosen to be optimized: the spring mass and its natural frequencies. This method is then applied to the case of circular cross section helical spring, and then optimization results are presented and discussed.

Yokota, Taguchi and Gen [8] formulated an optimal weight design problem of herical spring for a constrained allowable shearing stress, number of active coils and coil's mean diameter as a nonlinear integer programming(NIP) problem and solved it directly by keeping the nonlinear constraint by using an improved genetic algorithm (GA). 
Zhao, Chen and Zhou [9] presented a robust optimization mathematical model of the cylindrical helical compression spring. To minimize the error and maximal variations of spring stiffness coefficient related with structure parameters and its tolerances is chosen as its objective function, and the acceptable region is formed by some constraints.

Liu, Liu and Zhao [10] established a multiobjective optimal model of the cylindrical helical spring based on robust and reliability optimization design theory. The objective was to obtain a spring with minimum mass and maximum natural vibration frequency and minimum reliability sensitivity. Some parameters of the spring are taken as random variables in this model and the reliability target is taken as the constrained condition. This multiobjective optimal problem is transformed into a single-objective optimal problem by using the multiplication and division method. Further, an improved swarm algorithm which can reasonably deal with hybrid discrete variables is used to solve this problem.

Krużelecki [11] presented the parametrical optimization problem of helical springs against instability. Such an initial distribution of a helix angle and radius of a spring is sought in the assumed class of functions which ensure maximal value of the critical axial compressive force under equality and inequality constraints. The volume of the spring material, the initial compression rigidity and also the slenderness ratio of the spring are considered as the equality constraints. The inequality constraints are connected with: a strength condition, a condition of closing up of neighbouring coils, and geometrical conditions in the initial and compressed state.

The optimal design of helical springs is over 100 years old (Henderson 1884-1885) [11], but a serious mistake in optimization design of helical springs has been widely used by researchers and designers for a long time. So far, in almost all of the literature, such as in [2]-[11], wire diameter $d$, mean coil diameter $D$ and number of active coils $n$ are design variables in the optimization design model of helical springs. In fact, only one variable ( $d$ or $D)$ is independent variable in the three design variables $(d, D$ and $n)$. Dependent variables can influence solving efficiency of optimization design. The dependent variables are also possible to calculate wrong results. Therefore, it is imperative to address the error of design variables in optimum design of helical springs. In [12] we put forward this question, here we further discuss and correct this problem in optimum design of helical springs.

\section{DESIGN OF HELICAL SPRING}

Helical springs can be classified into helical compression spring and helical extension spring according to the direction and the nature of the force exerted by the spring when it is deflected. In this section, the helical compression spring is discussed as an example.

\section{A. Principal Formulas of Helical Compression Spring}

In Fig. 1, a helical spring of circular cross section is composed of a slender wire of diameter $d$ wound into a helix of mean coil diameter $D$ and pitch angle $\alpha$. Fig. 1 shows loads $F$ and deflections $\lambda$ on helical compression spring.

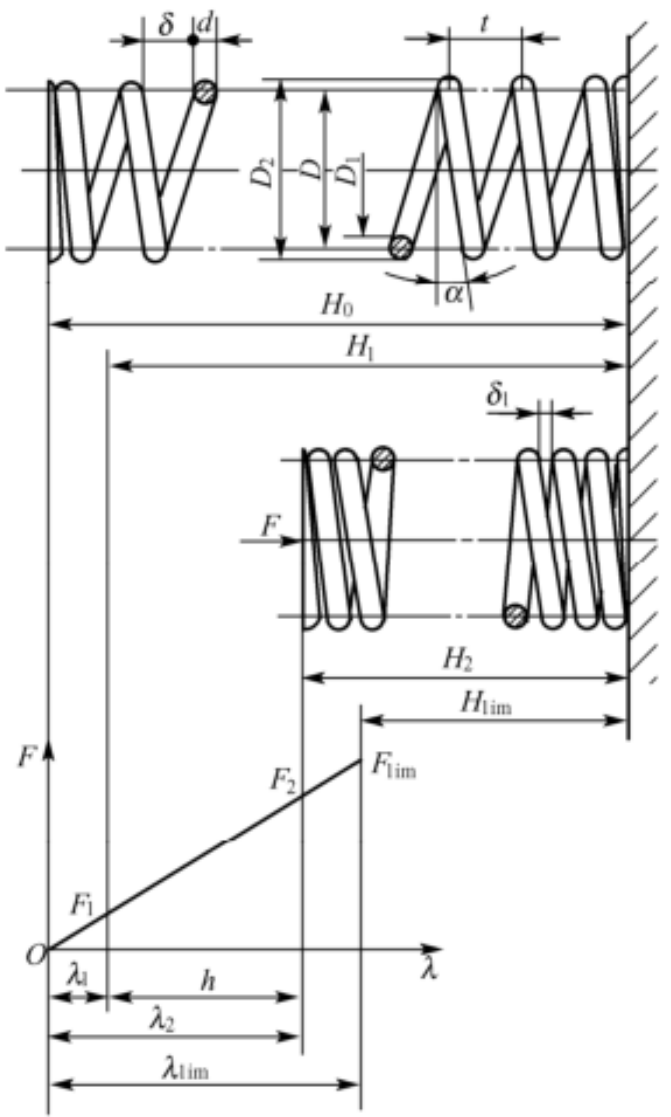

Fig. 1. loads and deflections on helical compression spring.

The following paragraphs define the parameters used to describe and analyze the performance of helical compression spring [1], [13], [14].

The ratio of the mean diameter $D$ of the spring to the wire diameter $d$ is termed the spring index $C$.

$$
C=\frac{D}{d}
$$

The maximum shear stress $\tau$, known as the Wahl equation, is

$$
\tau=\frac{8 K F D}{\pi d^{3}}=\frac{8 K F C}{\pi d^{2}}
$$

The Wahl factor $K$ is defined by

$$
K=\frac{4 C-1}{4 C-4}+\frac{0.615}{C}
$$

Therefore, the wire diameter $d$ is obtained from

$$
d=\sqrt[3]{\frac{8 K F D}{\pi[\tau]}}=\sqrt{\frac{8 K F C}{\pi[\tau]}}
$$

where $[\tau]=$ maximum allowable shear stress

The linear deflection equation of the helical springs is 


$$
h=H_{1}-H_{2}=\lambda_{2}-\lambda_{1}=\frac{8 D^{3}\left(F_{2}-F_{1}\right) n}{G d^{4}}
$$

where $h=$ operating stroke (See Fig. 1.)

$H_{1}=$ installed length (See Fig. 1.)

$\mathrm{H}_{2}=$ operating length (See Fig. 1.)

$F_{2}=$ operating load (See Fig. 1.)

$F_{1}=$ installed load (See Fig. 1.)

$\lambda_{2}=$ operating deflection (See Fig. 1.)

$\lambda_{1}=$ installed deflection (See Fig. 1.)

$\mathrm{G}=$ modulus of elasticity of the material in shear

$n=$ number of active coils

Thus the number of active coils $n$ is calculated from the linear deflection equation

$$
n=\frac{G d^{4}}{8 D^{3}\left(F_{2}-F_{1}\right)}\left(\lambda_{2}-\lambda_{1}\right)
$$

\section{B. Design Calculations of Helical Compression Spring}

The design of helical-coil springs involves selection of a material, and determination of the wire diameter $d$, mean coil diameter $D$, number of active coils $n$, and other spring parameters so that the desired load-deflection response is obtained, without exceeding the design stress under the most severe operating conditions. According to the space, the basic sizes of spring could be determined. For example, the maximum out diameter, the minimum inner diameter, spring rate, the maximum deflections and the maximum loads during assembly [1], [13], [14].

\section{OPtIMUM DESIGN OF HELICAL SPRINGS}

\section{A. Variables of Optimization Design}

In general, any design has design variables, such as structure's cross-section sizes, beam's length, or material parameters, etc. Among these design variables, some are independent variables and others are dependent variables. All design parameters in the optimization design must be independent variables in mathematical model for optimization of design, which influences the behavior of the systems to be optimized.

The important step in the optimum design of practical problem is to identify a set of variables that describe the system, called the design variables. In general, these are referred to as optimization variables and are regarded as free because we should be able to assign any value to them. Different values for the variables produce different designs. The design variables should be independent of each other as far as possible. If they are dependent, their values cannot be specified independently because there are constraints between them [2].

If proper design variables are not selected for a problem, the formulation will be either incorrect or not possible. As many independent parameters as possible should be designated as design variables at the problem formulation phase. Design variables should be independent of each other as far as possible. If they are not, there must be some equality constraints between them [2].

\section{B. Analysis of Error in Optimum Design of Helical Spring}

The objective of the design of helical compression springs is to specify the geometry for the spring to operate under specified limits of load and deflection, possibly with space limitations, also [13]. It is first step to select a material of spring according to the maximum allowable shear stress $[\tau]$ of spring material when operating load $F_{2}$, installed load $F_{1}$, operating deflection $\lambda_{2}$ and installed deflection $\lambda_{1}$ (operating stroke $h=\lambda_{2}-\lambda_{1}$ ) are given. The second step is to determine the mean diameter $D$ or the spring index $C$ and solve the wire diameter $d$ by (4). The next step is to solve number of active coils $n$ by (6).

The objective function and constraints of optimum design of helical springs can be determined according to the different requirements of the optimization, see [2], [14]-[19].

To date, all the authors such as the researchers of [2]-[11] have selected the wire diameter $d$, the mean coil diameter $D$ and the number of active coils $n$ as design variables of helical springs in the examples of the monographs on optimization.

Obviously the number of active coils $n$ is a dependent variable in (6), which is the dependent variable of the wire diameter $d$, the mean coil diameter $D$, the installed load $F_{1}$, the operating load $F_{2}$, the installed deflection $\lambda_{1}$ and the operating deflection $\lambda_{2}$. When $F_{1}, F_{2}, \lambda_{1}$ and $\lambda_{2}$ are known, $n$ is the dependent variable of $d$ and $D$. Once $D$ and $d$ are determined, $n$ is the only value that is determined in (6). Generally speaking, the number of active coils $n$ is changed with condition that wire diameter $d$ and mean diameter $D$ are first solved. Therefore, the number of active coils $n$ should not be used as a design variable in optimization design of helical spring. As the design variable, the number of active coils $n$ that depends on $d$ and $D$ in (6) not only cannot meet the requirements of the design objective of helical springs but also may get wrong design results of helical springs without equality constraint (6).

On the surface, it appears that there is only one independent variable between the wire diameter $d$ and the mean diameter $D$ in (4). Considering $[\tau]$ in (4) is a maximum allowable shear stress of helical springs, the shear stress $\tau$ of helical spring in the actual design is less than $[\tau]$. The value of $\tau$ in helical spring varies with different values of $D$ and $d$ in (2). $D$ and $d$ are independent variables so that they can be used as design variables in all optimization design of helical springs.

Reference [2] emphasizes that design variables should be independent of each other as far as possible. By contrast, the example of optimum design in [2] not only used the wire diameter $d$, the mean coil diameter $D$ and the number of active coils $n$ as design variables of helical springs but also did not have equality constraints between them.

If some design variables are dependent variables, there must be some equality constraints between them. Instead, almost none of references such as [5]-[9] and [15]-[19] constrained the number of active coils $n$ by (6), so that they got the wrong results of $n$. Table I shows the comparison of wrong and right results in [15]-[19]. Wrong value of the number of active coils $n$ not only has no practical value, but also may lose the meaning of optimization. 
TABLE I: THE COMPARISON OF WRONG AND RIGHT RESULTS IN [15]-[19]

\begin{tabular}{ccccccccc}
\hline \hline Reference & $F_{1}(\mathrm{~N})$ & $F_{2}(\mathrm{~N})$ & $h(\mathrm{~mm})$ & $d(\mathrm{~mm})$ & $D(\mathrm{~mm})$ & $n$ & $n$ in $(6)$ & $G(\mathrm{Mpa})$ \\
\hline$[15]$ & 272 & 680 & 10.16 & 5.5 & 35 & 3.5 & 5.22 & 78500 \\
{$[16]$} & 272 & 680 & 10.16 & 6 & 38 & 4.75 & 5.77 & 78500 \\
{$[17]$} & 272 & 680 & 10.16 & 6 & 35 & 2.75 & 7.39 & 78500 \\
{$[18]$} & 200 & 450 & 10 & 3.3 & 15.5 & 10.5 & 12.5 & 78500 \\
{$[19]$} & 272 & 680 & 10.16 & 5.5 & 38 & 4.5 & 4.07 & 78500 \\
\hline \hline
\end{tabular}

\section{CONCLUSION}

The design variables should be independent of each other as far as possible. If they are dependent, there must be some equality constraints between them.

The number of active coils $n$ is a dependent variable in (6). When the installed load $F_{1}$, the operating load $F_{2}$, the installed deflection $\lambda_{1}$ and the operating deflection $\lambda_{2}$ are known, $n$ is the dependent variable of the wire diameter $d$ and the mean diameter $D$. Once $D$ and $d$ are determined, $n$ is the only value that is determined in (6). Therefore, the number of active coils $n$ should not be used as a design variable in optimization design of helical spring. The number of active coils $n$ as the design variable not only cannot meet the requirements of the design objective of helical springs but also may get wrong design results of helical springs without equality constraint.

The wire diameter $d$ and the mean diameter $D$ are independent variables in (2), so that they can be used as design variables in all optimization design of helical springs. As design variables, $D$ and $d$ are more reasonable in the actual optimization process of helical springs design.

It is imperative to correct this prevalent error in the optimal design of helical springs.

\section{REFERENCES}

[1] M. F. Spotts, T. E. Shoup, and L. E. Hornberger, Design of Machine Elements, 3rd ed. U.S.A.: Prentice-Hall, Inc., 2004, ch. 9.

[2] J. S. Arora, Optimum Design, 3rd ed. New York: Academic Press of Elsevier, 2012, ch. 2, pp. 17-25.

[3] S. Sadhu and S. V. Kulkarni, " Graphical method for optimum design of helical springs," Journal of the Institution of Engineers (India): Mechanical Engineering Division, vol. 57, pp. 72-77, Sep. 1976.

[4] B. S. Azzam, "An optimum design for composite helical springs," in Proc. the Institution of Mechanical Engineers, Part D: Journal of Automobile Engineering, vol. 224, pp. 347-354, Mar. 2010.

[5] I. Pöllänen and H. Martikka, "Optimal re-design of helical springs using fuzzy design and FEM," Advances in Engineering Software, vol. 41, pp. 410-414, Mar. 2010.

[6] F. Qin-man, W. Yong-hai, L. Kun, and W. Feng, "Multi-objective optimization design of automobile suspension helical spring," in Proc. ICIC 2010 - 3rd International Conference on Information and Computing, pp. 219-222, vol. 1, Wuxi, China, 2010.

[7] M. Taktak, K. Omhenia, A. Alouia, F. Dammakb, and M. Haddarb, "Dynamic optimization design of a cylindrical helical spring," Applied Acoustics, vol. 77, pp. 178-183, Mar. 2014.

[8] T. Yokota, T. Taguchi, and M. Gen, "A solution method for optimal weight design problem of herical spring using genetic algorithms," Computers \& Industrial Engineering, vol. 33, pp. 71-76, Oct. 1997.

[9] Z. Hong, C. Gang, and Z. Junzhe, "The robust optimization design for cylindrical helical compression spring," in Proc. 2011 International Conference on Material Science and Information Technology, pp. 2201-2205, vol. 433-440, Singapore, 2012.

[10] Y. J. Liu, M. Liu and M. Zhao, "Robust optimization design for the cylindrical helical spring based on the improved particle swarm algorithm," in Proc. the Second International Conference on Mechatronics and Automatic Control, pp. 953-960, Beijing, China, 2014.
[11] J. Krużelecki, "Parametrical optimization of compression helical springs against instability," Structural optimization, vol. 13, pp. 205-212, Apr. 1997.

[12] Y. X. Li, S. P. Chen, and W. Q. Zhang, "A prevalent error in optimization design of helical springs," in Proc. 2014 The $3 \mathrm{rd}$ International Conference on Automatic Control and Mechatronic Engineering, Advanced Materials Research, pp. 324-327, Vols. 1006-1007, Xiamen, China, 2014.

[13] R. L. Mott, Machine Elements in Mechanical Design, 3rd ed. U.S.A.: Prentice-Hall, Inc., 2002, ch. 19, pp.655-682.

[14] Spring Manual, 1st ed., China Machine Press, 1997, pp. 205-248.

[15] L. Z. Chen, Optimum Design Method of Engineering Discrete Variables: Principle and Application, 1st ed. Beijing, China: China Machine Press, 1989, ch. 13, pp. 264-269.

[16] Q. Wang and W. B Wang, Reliability Design of Common Machine Elements and Components, 1st ed. Beijing, China: China Machine Press, 1996, ch. 12, pp. 300-305.

[17] H. Z. Huang, Fuzzy Optimization Principle and Application of Machinery Design, 1st ed. Beijing, China: Science Press, 1997, ch. 7, pp. 169-172.

[18] H. Wang and R. Y. Wei, "Optimum design of cylinder helix spring based on GA and compound form method," Journal of Suzhou University (Engineering Science Edition), vol. 29, pp. 49-52, Apr. 2009.

[19] X. P. Gong, Y. J. Liu, and L. I. Cui, "Reliability optimization design of cylindrical helical spring," Journal of Air force Engineering University(Natural Science Edition), vol. 11, pp. 77-80, Apr. 2010.

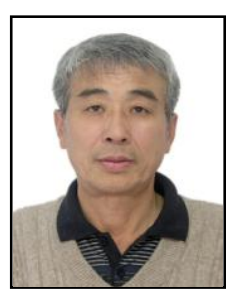

Yongxian Li was born in Taiyuan, China, on April 29, 1950. He received his bachelor of engineering degree in engineering machinery from Taiyuan Heavy Machinery Institute (Now the name is Taiyuan University of Science and Technology), Taiyuan, China from 1978 to 1982. He received his master of engineering degree in engineering machinery from Taiyuan Heavy Machinery Institute, Taiyuan, China from 1986 to 1990 . The major field of study is intelligent optimization, design and analysis of experiments, mechanical design, automotive design, and car maintenance.

$\mathrm{He}$ is a professor in the Department of Automotive Engineering at Weifang Business Vocational College and a Professor in the Department of mechanical engineering of College Engineering at Zhejiang Normal University. He was a professor of the Xiamen University Tan Kan Ken College, a professor of the Tianjin University of Technology and Education, and $\mathrm{a}$ an associate professor of Taiyuan Heavy Machinery Institute. He has published several papers on optimal design and robust design, such as: Y. X. Li, Q. G. Meng, and Z. G. Li, "Robust design based on three stage design and fuzzy theory for helical springs," Journal of Mechanical Strength (China), vol. 23, pp. 198-201, Feb. 2001; Y. X. Li and J. Z. Li, "Orthogonal optimization algorithm of swarm intelligence based on the analysis of variance ratio," in Proc. 2009 Second International Symposium on Computational Intelligence and Design, pp. 389-392, Sanya, China, 2009; Y. X. Li, W. Q. Zhang, and S. P. Chen, "Reliability optimization design of automobile propeller shaft," Advanced Materials Research, vols. 1049-1050, pp. 842-845, Aug. China, 2014. In recent years, he has devoted himself to the research of intelligent optimization, and has developed new and original theoretical achievements (unpublished).

Prof. Li is a member of the Chinese Mechanical Engineering Society, a member of the Society of Automotive Engineers of China and a member of the Chinese Association Applied Statistics. 